\title{
Representações do Brasil em museus de Portugal
}

Sandra Guedes ${ }^{1}$ Mário Moutinho ${ }^{2}$

Resumo: $O$ artigo pretende discutir quais representações sobre o Brasil são encontradas em museus portugueses. O levantamento de informações, de caráter documental e qualitativo, foi feito em40 museus sob o olhar de um visitante comum que observa e tira suas conclusões com base nas informações que lhe são oferecidas durante a visita, mesmo entendendo que o processo de montagem das exposições transcende o que está à vista. Partiu-se do princípio de que as exposições dos museus ajudam a construir representações que são endossadas pela aura de verdade que as circunda. Entre as representações analisadas, destacam-se a do Brasil como importante colônia fornecedora de riquezas para Portugal, presente nos museus mais tradicionais do país, e outra que evidencia as relações históricas dos dois países por meio de algumas personagens portuguesas como Cabral e Pedro I (IV de Portugal), vistas principalmente em museus de fora da capital. Assim, percebese que a estreita relação que o Brasil teve com Portugal enquanto colônia ainda está ajudando a construir as representações que este país faz daquele.

Palavras-chave: Museus; Representações; Portugal; Brasil.

Abstract: The article intends to understand what representations about Brazil are found in Portuguese museums. The survey

\footnotetext{
${ }^{1}$ Sandra Paschoal Leite de Camargo Guedes, Doutorada em História Social pela Universidade de São Paulo, Brasil(1992), Professora Pesquisadora da Universidade da Região de Joinville,Brasil. sandraplcguedes@gmail.com

${ }^{2}$ Mário Moutinho, Doutorado em Antropologia pela Universidade de Paris VII Jussieu, Professor e investigador no Departamento de Museologia da Universidade Lusófona de Lisboa
} 
information, document and qualitative ones, was done in 40 museums by as a common visitor who observes and draws conclusions from the information that is offered to him during the visit, even understanding that the exhibits assembly process transcends what it is in sight. It is assumed that the exhibits of the museums help to build representations that are endorsed by a real aura that surrounds them. Among the representations, we have one that shows Brazil as an important provider of wealth for Portugal, which is in the most traditional museums in the country, and another one that presents the two countries historical relationship through some Portuguese characters like Cabral and Pedro I (IV of Portugal), more common mainly in museums located out of the capital. Then, we can see that the close relationship that Brazil had with Portugal as a colony is still helping to build the representations that one country has about the other one.

Keywords: Museums; Representations; Portugal; Brazil.

\section{Introdução}

Portugal e Brasil têm relações históricas muito fortes, construídas principalmente durante os três séculos de colonização. Apesar de essas relações terem se iniciado no século XVI, segundo o Instituto Brasileiro de Geografia e Estatística (IBGE, 2000), a imigração de portugueses no Brasil deu-se, com maior intensidade, na primeira metade do século XVIII, quando aconteceu "a febre do ouro", e entre o fim do século XIX e 1930, quando mais de um milhão de portugueses chegaram ao Brasil, como demonstra a tabela 1.

Tabela 1 - Imigração de portugueses no Brasil 1500-1991

$\begin{array}{ll}\text { Anos } & \text { Número de imigrantes } \\ 1500-1700 & 300.000 \\ 1701-1760 & 600.000 \\ 1808-1817 & 24.000\end{array}$




$\begin{array}{ll}1827-1829 & 2.004 \\ 1837-1841 & 629 \\ 1856-1857 & 16.108 \\ 1881-1900 & 316.204 \\ 1901-1930 & 754.147 \\ 1931-1950 & 148.699 \\ 1960-1970 & 163.000 \\ 1981-1991 & 4.605 \\ \text { Fonte: adaptada de IBGE (2000) }\end{array}$

Entre 1960 e 1970 ocorreu um novo movimento migratório, motivado sobretudo pelas guerras coloniais na África e por conflitos políticos internos em Portugal, quando cerca de163 mil pessoas deixaram o país em direção ao Brasil (IBGE, 2000). Nas últimas décadas do século $X X$, com mudanças no quadro político e econômico em Portugal e no Brasil, no entanto, aconteceu o movimento inverso, quando muitos emigrantes portugueses retornaram a Portugal e mais de 1.500 .000 brasileiros deixaram o Brasil à procura de novas oportunidades; muitos escolheram Portugal como destino (IBGE, 2000).Atualmente, estima-se que mais de 60 mil brasileiros vivam em Portugal, sendo considerada a maior população estrangeira no país (MALHEIROS, 2007, p.142). A atração de brasileiros por Portugal pode ser justificada por uma série de fatores, tais como:

A língua comum, potenciada por um intercâmbio literário pujante e pelo "imaginário realista" da telenovela, é traço de união indelével; a informalidade no trato e o "jeito" brasileiro de comunicar vêm revolucionando vastos sectores de serviços em Portugal com particular realce para o comércio de retalho, a hotelaria e a restauração; a omnipresença do futebol brasileiro nos relvados e nos media são fatores que elevam a presença da comunidade brasileira entre nós a um estatuto 
absolutamente indiscutível; as efemérides passadas e futuras convocam ambas as pátrias a uma celebração continuada: foram os Quinhentos Anos de Cabral (2000), serão os Duzentos Anos da Viagem da Corte Portuguesa para o Brasil (2007-2008) (MALHEIROS, 2007,p. 8).

Para além desses fatores, a entrada de Portugal na Comunidade Econômica Europeia (CEE) em 1986 e a melhoria nos sistemas de transporte e infraestrutura, entre outros aliados a problemas econômicos pelos quais o Brasil passou naquele período, propiciaram a ida de brasileiros com alta qualificação profissional para Portugal, ao contrário do que se deu mais recentemente, quando a chegada de brasileiros com menor qualificação profissional e baixa escolaridade passou a ser vista como um problema a ser encarado pelo país(MALHEIROS, 2007).

Fora a forte presença de brasileiros residindo em Portugal, é significativo o aumento de turistas brasileiros no país. Em 2013 foi registrado crescimento de 7,4\% em relação ao ano anterior e,

segundo os dados do Instituto Português de Estatística(INE), o Brasil foi o quinto mercado emissor com maior crescimento no número de dormidas em hotéis portugueses, atrás dos Estados Unidos (16,4\%), França (14,5\%), Irlanda (11,3\%) e Reino Unido (8,6\%)(HORTA, 2014).

Esses dados e o fato de o Brasil ser hoje a sétima maior economia do mundo (BRASIL, 2000) devem contribuir para que um olhar especial por parte das instituições ligadas ao turismo seja lançado para os brasileiros.

Essas relações, passadas e presentes, entre brasileiros e portugueses ajudaram, em diferentes momentos históricos, a construir inúmeras representações sobre o "outro" de ambos os lados. Malheiros (2007, p.12) evidencia que muitas representações 
dos brasileiros podem ser encontradas atualmente em Portugal, “como [os] estrangeiros 'mais próximos' e simpáticos [...], 'conversadores' ou 'alegres e abertos', mas não necessariamente trabalhadores empenhados ou muito produtivos", além de serem claras, segundo o autor, algumas representações bastante pejorativas associadas à mulher brasileira.

Nesse contexto, pergunta-se: existirão outras formas de representar o Brasil e os brasileiros em Portugal? Como os museus, instituições tradicionalmente consideradas "reprodutoras da verdade", representam o Brasil em Portugal? Essas representações estariam ligadas à história que une Brasil e Portugal como colônia e colonizador ou estariam mais ligadas a essas representações criadas mais recentemente? São essas questões que este artigo pretende abordar.

\section{Representações e museus}

A importância de conhecer as representações que a sociedade tem a respeito de algum objeto da realidade está na capacidade que elas têm de provocar ações sobre essa realidade. Segundo os psicólogos sociais Serge Moscovici (2003) e Denise Jodelet (2007), as representações possuem o aspeto funcional de formar e orientar comportamentos, dominar e organizar o ambiente e se comunicar socialmente. Elas refletem a maneira como os indivíduos pensam, agem e procuram compreender o sentido de suas ações e seus pensamentos. As representações são construídas baseadas em informações preexistentes, de práticas cotidianas: "Elas se constituem sob uma base de conhecimento já adquirido em que deve ser também sopesada a história do grupo que a construiu" (BÔAS; SOUSA, 2007, p.155). São, portanto, historicamente construídas, e conhecer essa historicidade é fundamental para entender as representações existentes. As representações são, ao mesmo tempo, produto cultural construído socialmente e processo, na medida em que influenciam e são influenciadas pela sociedade, e a cultura desempenha papel importante na sua formação. 
O historiador francês Roger Chartier (1990, p.17)também acredita que as representações do mundo social "são sempre determinadas pelos interesses dos grupos que as forjam" e que as "lutas de representações têm tanta importância como as lutas econômicas para compreender os mecanismos pelos quais um grupo se impõe ou tenta se impor" em seu meio social.Para ele, as representações que os diferentes grupos fazem de si mesmos e da realidade contribuem para a formação e legitimação de sua própria identidade social, interferindo diretamente em suas práticas ou ações na sociedade. Os estudos sobre as representações sociais podem resultar em intervenções de diferentes naturezas na realidade presente, como

Auxiliar a formulação de projetos, a tomada de decisões, a resolução de problemas;[e] ajudar o esclarecimento da relação que os sujeitos têm com sua experiência para construir, numa situação de interação, um conhecimento dos processos nos quais os sujeitos são inscritos e dar-lhes um novo sentido (JODELET, 2007, p.58).

Partindo desse pressuposto, acredita-se que as representações sociais são uma importante ferramenta para o desenvolvimento de trabalhos que tenham objetivos de interação social, como aqueles voltados à museologia social. A utilização das representações sociais para esse fim, segundo o museólogo Mário Chagas (2009), já havia acontecido na década de 1950 pelo antropólogo Darcy Ribeiro para a elaboração do Museu do Índio no Brasil. Ribeiro baseou-se no conhecimento das representações que a sociedade brasileira tinha sobre o índio para planejar uma exposição que desmistificasse os estereótipos preconceituosos existentes sobre o indígena na época. É claro que, ao apresentar determinadas versões da realidade, aqui quanto ao indígena, o antropólogo propunha uma visão científica do fato, aquela visão que ele pensava ser a correta, que também é datada e, como todas, deve ser 
constantemente revisada e atualizada.

Não é novidade afirmar que os museus são campo fértil para a construção de representações, já que são reconhecidos pelo seu poder de dizer a "verdade" e de serem guardiões da memória (CHAGAS, 2002; SANTOS,2004).Os museus, por intermédio de suas exposições, têm o poder de atribuir valores às memórias e aos objetos de determinados grupos sociais, os quais serão representados e consequentemente "lembrados" mediante uma narrativa que institucionalizará essas memórias. Os museus possuem também influência política, pois a sua existência e atribuição estão envolvidas em esferas de relações políticas e de poder complexas. Seus espaços não têm apenas a atribuição da guarda de objetos e documentos, mas a da difusão de saberes, memórias e identidades.

Nesse sentido, é necessário compreender o espaço museal como reflexo das complexas relações culturais, políticas e sociais que o englobam, pois pelo seu acervo as histórias individuais e coletivas são representadas.

Compreender esse discurso, composto de som e silêncio, de cheio e vazio, de presença e ausência, de lembrança e esquecimento, implica a operação não apenas com o enunciado da fala e suas lacunas, mas também a compreensão daquilo que faz falar, de quem fala e do lugar onde se fala (CHAGAS, 2002, p.43).

O que é selecionado para fazer parte de uma exposição e a forma como se apresenta estão cercados de intencionalidades que procuram legitimar verdades institucional ou pessoalmente constituídas. Nenhum discurso é neutro ou inocente, como disse Chagas (2002) na citação anterior, e a não menção e o esquecimento também são formas de discurso - visão referendada por aqueles que trabalham com a análise do discurso, como Fairclough (2001), por exemplo. Ele discute o discurso como 
representação e significação do mundo na medida em que constitui e constrói o mundo em significado. Ao pensar que o discurso se constrói socialmente e que ele constitui representação do mundo, pode-se dizer que o discurso é reflexo de representações sociais, mas ao mesmo tempo ajuda a construir novas representações. Trata-se de um processo dialético de contínuas elaborações e desconstruções de significados.

É dessa maneira que entendemos os discursos ou as narrativas presentes nos museus, ou seja, como resultado de representações sociais que são construídas e que se constróem contínua e socialmente. A "aura de verdade" que envolve as exposições museais permite que as representações construídas com base nessas exposições também tenham força maior do que as representações provenientes de outras tantas instâncias.

Assim, a prática política é a categoria superior. Além disso, o discurso como prática política é não apenas um local de luta de poder, mas também um marco delimitador na luta de poder: a prática discursiva recorre a convenções que naturalizam relações de poder e ideologias particulares e as próprias convenções, e os modos em que se articulam são um foco de luta (FAIRCLOUGH, 2001, p.94).

O poder político das representações construídas por meio dos discursos museais tem sido evidenciado com mais intensidade nas últimas décadas na medida em que foram construídos grandes museus que têm as relações políticas e/ou econômicas entre países seu maior objetivo. Um exemplo pode ser o Museu do Oriente, em Lisboa, cujo discurso reflete o poderio de países que atualmente se destacam na economia mundial e que se tornaram, para além das relações passadas de dominados e dominadores, parceiros políticos e econômicos de grande importância no cenário atual. Instituído pela Fundação Oriente em 2008, o Museu do Oriente, identificado em seu site como "uma ponte entre culturas remotas", trata as 
relações históricas de Portugal com o Oriente como um importante encontro entre culturas e o estabelecimento de novas relações comerciais entre Portugal e os países orientais ali representados, principalmente China e Îndia.

As suas coleções de arte portuguesa e asiática são a demonstração mais elevada dos encontros históricos entre o Ocidente e o Oriente. No mesmo sentido, as coleções que reúnem as tradições culturais da Ásia inteira são a demonstração da sua riqueza, da sua pluralidade e do seu génio, que queremos possa ser melhor conhecido em Portugal e na Europa. A abertura do Museu do Oriente, em 2008, marcou um novo ciclo na vida da Fundação. Os princípios que determinaram a sua criação mantêm-se, como se mantém a vontade de bem servir Portugal e a vocação de contribuir para o encontro entre Ocidente e Oriente e para uma relação entre civilizações em que o conhecimento, a arte e também as relações económicas substituam a ignorância, o fanatismo e a guerra. A ressurgência internacional da China e da Índia e a importância crucial das relações de Portugal e da Europa com a nova Ásia são hoje uma manifesta realidade. E se a diplomacia e as relações económicas são essenciais, elas terão, porém, de assentar, tal como no passado, nas artes, nas ciências e na cultura, que podem representar formas duradouras de convergência entre as grandes civilizações (FUNDAÇÃO ORIENTE, 2014).

As intenções políticas para a construção do Museu do Oriente estão claras no site institucional, como se pode ler na citação. O museu faz parte de um trabalho de diplomacia e relações internacionais que procura evidenciar uma "nova Ásia" que ressurge 
como potência internacional, ressignificando a antiga relação entre colonizador e colonizados. Diversos países asiáticos, como Macau e Goa, por exemplo, que foram colônias portuguesas, aparecem como produtores de riquezas e possuidores de uma cultura material e imaterial de destaque pela imponência e pelo valor estético. Nesse e em outros museus, os objetos escolhidos, os textos, a maneira como são apresentados ou não determinados acervos denunciam as representações que se quer transmitir sobre determinado fato.

Un museo puede ser visto como una selección en términos de su acervo o colección, y como una elección en cuanto a la versión que decide difundir de sus fundos - materiales e inmateriales - y su búsqueda de conservación, conocimiento y disfrute. Enla actualidad, el museo es el gran productor de sentidos a partir de servicios y mercancías culturales ponderadas por diversas circunstancias, objetos $y$ textos que buscan, desde sus espacios museográficos, ser articulados en ese gran texto que constituye una exhibición(ESTRADA, 2012, p.12) $)^{3}$.

Se as ex-colônias portuguesas do Oriente estão sendo ressignificadas, principalmente pelas exposições do Museu do Oriente 4 ,buscando mostrar uma "nova Ásia", pergunta-se como o Brasil, também ex-colônia portuguesa, está sendo representado nos museus portugueses.

\footnotetext{
${ }^{3}$ Um museu pode ser visto como uma seleção em termos de acervo e coleção e como uma eleição com relação à versão que se pretende difundir sobre seus fundos - materiais e imateriais - e sobre as decisões acerca de conservação, conhecimento e desfrute. Na atualidade, o museu é um grande produtor de sentidos por meio de serviços e trocas culturais cercadas de diversas circunstâncias, objetos e textos que buscam, em seus espaços museográficos, ser articulados nesse grande texto que constitui uma exposição(tradução livre).

4 Obras de arte provenientes das ex-colônias portuguesas do Oriente estão presentes e em grande quantidade em exposições de inúmeros museus do país.
} 


\section{Discussão dos resultados}

Para responder à questão colocada, foi desenvolvida uma pesquisa de campo que envolveu 82 museus de Portugal. Para a seleção dessa amostra ${ }^{5}$,foram estabelecidos alguns critérios: a) museus de Lisboa, capital do país e onde está concentrada a maioria dos museus de Portugal; b) museus mais visitados do país ; c) museus das universidades de Lisboa, Coimbra e Porto, que sabidamente possuem acervos brasileiros ${ }^{7}$; d) museus identificados em pesquisa em sites que mostram alguma relação com o Brasil; e) informações de especialistas e trabalhadores de museus portugueses $^{8}$. Nessa primeira fase não foram priorizados os museus de arqueologia, os ecomuseus, os museus locais e os museuscasa ${ }^{9}$,por serem instituições que abordam assuntos específicos de Portugal.

A pesquisa de campo desenvolveu-se, preferencialmente, sem a identificação da pesquisadora aos responsáveis dos museus visitados, a fim de não influenciar no tipo de atendimento dado. A visita deu-se como a de um indivíduo comum que vê o museu sem mediação humana. A coleta de dados envolveu a observação e o registro fotográfico dos objetos e textos presentes nas exposições ese transformaram em documentos de análise posterior. Deve-se salientar que só foram examinadas as exposições abertas ao público, ou seja, as exposições permanentes, temporárias ou reservas visitáveis abertas ao público no período em que se realizou

\footnotetext{
${ }^{5}$ A relação de museus do país ultrapassa dois mil.

${ }^{6}$ Foram utilizados dados do Instituto Nacional de Estatísticas de Portugal - Inquérito dos Museus de 2009. Disponível em:<http://www.imc-ip.pt/ptPT/recursos/estatisticas/ContentDetail.aspx>.Acesso em: 12 mar. 2014.

${ }^{7}$ Ver Santos (2004) e Schwarcz (1998).

8 Gostaria de agradecer especialmente as informações prestadas por Mário C.Moutinho, Judite Primo, António Nabais, Mário de Souza Chagas e Maria Cristina de Oliveira Bruno.

${ }^{9}$ Exceção feita àqueles que tivessem alguma informação de sua relação com o Brasil ou com brasileiros.
} 
a pesquisa de campo ${ }^{10}$. Não foram contemplados os acervos que se encontravam em reservas técnicas não visitáveis e, portanto, não acessíveis ao público. Também não foram consideradas informações de exposições passadas, às quais, assim sendo, a pesquisadora não teve acesso. Dessa forma, a amostra foi reduzida para 40 museus onde alguma referência ao Brasil ou aos brasileiros foi notada.

Para este artigo foram destacadas duas das principais representações encontradas: 1) Brasil como colônia produtora de riquezas; 2 ) país ligado a Portugal por elos muito fortes: seus heróis, que são portugueses - Pedro Álvares Cabral, D. João VI e D. Pedro I, IV de Portugal. Ambas as representações estão ligadas ao passado colonial do Brasil.

No primeiro tipo de representação está a maioria das exposições que têm alguma referência ao Brasil, principalmente as centradas em Lisboa e arredores. O Brasil aparece como grande produtor de ouro, de onde chegavam as riquezas para 0 enriquecimento de Portugal sobretudo no século XVIII, depois da descoberta de ouro e pedras preciosas na colônia. Essa representação parece que vem se mantendo desde o século XIX, como foi observado pela socióloga Myriam Santos (2004, p.281) quando afirmou que, "para os europeus, a maior riqueza do Brasil era sua natureza e não seu legado cultural". A afirmação da autora está respaldada nas representações de museus do século XIX que priorizavam aqueles países que tivessem alguma ligação com a antiguidade clássica, valor preponderantemente evidenciado pelos museus europeus naquele momento e que não podia ser encontrado no Brasil. Passado mais de um século, essa é, no entanto, a representação predominante encontrada sobre o Brasil na maior parte dos museus analisados. Considerando a via cronológica, após a independência do Brasil, em 1822, as referências ao país diminuíram muito nos museus, praticamente desaparecendo, havendo algumas menções bastante pontuais e que podem denotar a fragilidade política brasileira com o fim da tutela portuguesa.

\footnotetext{
${ }^{10}$ Entre fevereiro e maio de 2014.
} 
Essa representação pode ser vista, por exemplo, no Mosteiro dos Jerônimos, monumento mais visitado de Portugal ${ }^{11}$. A exposição Um Lugar no Tempo, de caráter permanente e bilíngue, apresenta uma linha do tempo que promete situar a história do mosteiro em cinco séculos, contextualizando-a com a história de Portugal e do mundo. O texto introdutório dessa exposição deixa claro que ela foi montada por meio de "uma seleção de factos e imagens que fornecem aos visitantes portugueses e estrangeiros 0 que desejamos que seja o necessário enquadramento histórico". Fica claro nessa apresentação que os organizadores tinham ciência de que estavam fazendo uma seleção de fatos e que essa seleção era a que eles acreditavam ser a mais correta entre tantas possíveis. Assim, como não poderia deixar de ser, o Brasil aparece na cronologia da exposição desde 1500 até a independência, em 1822, como parte de Portugal e produtor de riquezas para o país e, depois dessa data, insere-se na cronologia relativa ao restante do mundo.

A primeira menção, em 1500, aponta o português Pedro Álvares Cabral como o responsável pelo "descobrimento". A seguir, são mostrados fatos que propiciaram riquezas para Portugal, como a fundação do primeiro engenho de açúcar, em 1532; a "descoberta do ouro em vários locais do Brasil -Febre do ouro" (grifo deles), em 1697; e a "descoberta de diamantes no Brasil - Bahia, Minas Gerais e Mato Grosso", em 1728. Paralelamente à descoberta de ouro e diamantes no Brasil, os dados sobre Portugal na linha do tempo demonstram o enriquecimento do país por meio da construção de diversos palácios e igrejas monumentais, como a da talha dourada da nave e a do cruzeiro da Igreja de São Francisco, na cidade do Porto, toda adornada com ouro brasileiro, e a Capela de N. Senhora de Belém, no próprio Mosteiro dos Jerônimos, que D. João $\mathrm{V}$ mandou dourar e decorar "com valiosas alfaias".

Outras datas que aparecem na cronologia da exposição do

\footnotetext{
${ }^{11}$ O Mosteiro dos Jerônimos atendeu perto de 700 mil visitantes em 2012. Dados obtidos pelo Instituto dos Museus e da Conservação (IMC-IP). Disponível em: <http://www.imc-ip.pt/pt-PT/recursos/estatisticas/ContentDetail.aspx>. Acesso em: 12 mar. 2014.
} 
mosteiro e que não têm relação com as riquezas naturais do Brasil são: 1549, quando ocorreu "o início da missionação jesuítica no Brasil, com a chegada do padre Manuel da Nóbrega e seus companheiros"; 1822,quando a independência do Brasil foi "proclamada por D. Pedro I, IV de Portugal. Aclamado Imperador do Brasil, [e que] em 1831 abdicou em favor de seu filho Pedro II" aqui se salienta a segunda representação vista em vários museus: a relação dos dois países estabelecida por heróis comuns -; e 1889, que erroneamente está referida à abolição da escravatura, quando a abolição ocorreu um ano antes, assinada pela então Princesa Isabel, e não pela Imperatriz Isabel, como está na linha do tempo dos Jerônimos, e à proclamação da República.

Depois da separação política, o Brasil surge novamente na linha do tempo ligado à história de Portugal em 1855, quando aconteceu o "início de um grande fluxo emigratório para o Brasil". No mesmo ano é assinalada uma epidemia de cólera em Portugal, que pode justificar a necessidade de tantas pessoas saírem do país em direção a sua ex-colônia. O Brasil só volta à linha do tempo, e pela última vez, quase um século depois, em 1985,quando houve a "restauração da democracia no Brasil depois de 21 anos de ditadura militar", paralelamente a outros acontecimentos em prol da democracia ocorridos em outras partes do mundo, embora a linha do tempo continue até o ano 2000, quando a exposição foi inaugurada. Nota-se a inexpressividade do Brasil após sua separação política de Portugal.

Essa inexpressividade pode ser evidenciada em outros museus de Lisboa que tratam em suas exposições de assuntos em que o país poderia/deveria ter sido pelo menos citado. Quando diz respeito, por exemplo, à participação dos jesuítas na história de Portugal, principalmente na sua colônia na América do Sul, fato apontado na linha do tempo da exposição do Mosteiro dos Jerônimos, chamou especial atenção a ausência de qualquer menção sobre isso no Museu de São Roque. Esse museu, apesar de ter como missão "promover ações de conservação, estudo e divulgação do patrimônio artístico e cultural da Santa Casa da 
Misericórdia de Lisboa"12, foi montado na antiga sede da Companhia de Jesus em Lisboa e apresenta uma parte considerável de sua exposição voltada à história da Companhia de Jesus. Logo, esperavase encontrar alguma menção ao Brasil. No entanto, a referida exposição apresenta em seus textos e objetos apenas a catequese feita pelos jesuítas em Macau e na Índia, salientando alguns objetos valiosos trazidos desses locais. Novamente, o Brasil só aparece como produtor e fornecedor de ouro e diamantes, aqui para a elaboração da rica Capela de São João Baptista, anexa ao museu, e para a confeção, "pelos mais notáveis ourives e bordadores" de Roma, de grande parte dos objetos ali exibidos e que deveriam servir

a prover a Corte de Lisboa de um cenário litúrgico à altura de suas ambições. Pretendia-se também reforçar o efeito político-diplomático de projecção além fronteiras e exibir uma capacidade financeira sem limites, por molde a dissipar, da mais ostensiva forma, toda a dúvida em contrário ${ }^{13}$.

Atribui-se o valor ao ouro e às obras de arte produzidas com essa matéria-prima por artesãos provenientes da própria Europa que davam a Portugal, como cita o texto, a projeção internacional de um país com "capacidade financeira sem limites". A importância do ouro brasileiro é inegável, porém há uma questão de omissão bastante intrigante: por que não há qualquer menção à participação dos jesuítas no Brasil enquanto ela é lembrada para as ex-colônias do Oriente? Muitos objetos expostos na mostra poderiam ter sido originados também do Brasil, já que é grande a semelhança entre a cultura material que representa os jesuítas nesse país e aquela presente na exposição. Nesse caso, a falta de acervo poderia ser uma resposta, contudo não justifica a total omissão, também nos

\footnotetext{
${ }^{12}$ Ver: <http://www.museu-saoroque.com/>.

${ }^{13}$ Fragmento de texto da exposição do Museu de São Roque, visitado em 7 de março de 2014.
} 
textos da exposição, do trabalho desenvolvido pelos jesuítas não só em relação à catequese dos indígenas e à expansão das fronteiras brasileiras ainda durante a fase colonial, mas principalmente à educação escolar que serviu de base para o sistema escolar brasileiro(ALMEIDA, 2000).

Outro exemplo de omissão associado à cultura brasileira pode ser observado no Museu da Farmácia, onde o conhecimento farmacêutico em diferentes épocas e relativo a praticamente o mundo todo é representado, todavia, mesmo na parte referente às Américas, nada existe acerca do Brasil, quer seja sobre o conhecimento dos indígenas, quer seja quanto aos avanços científicos mais recentes. Nota-se que a América é largamente representada com objetos e textos acerca da cultura material asteca, maia e inca, entretanto nenhuma palavra se diz sobre o conhecimento dos indígenas brasileiros. Essa postura é no mínimo estranha se pensarmos na quantidade de relatos relativos às populações indígenas brasileiras que foram elaborados durante os três séculos de domínio português.

No entanto a representação do Brasil como fornecedor de riquezas para Portugal está presente em vários outros museus como, por exemplo, no Palácio Nacional de Mafra, que está entre os cinco monumentos mais visitados do país" ${ }^{14}$ e é considerado "o mais importante monumento do barroco português", segundo a "Notícia histórica" afixada em uma das colunas do pátio de entrada do palácio. Esse texto, que também se encontra no fôlder de divulgação do palácio, explicita que a utilização do ouro oriundo do Brasil foi determinante para a construção e a suntuosidade daquele edifício. A mesma observação é feita nas visitas guiadas ao Palácio da Bolsa, em Porto, quando se explica aos visitantes que a madeira que se vê nos assoalhos e no mobiliário, assim como o ouro das paredes e dos objetos de decoração, é proveniente do Brasil.

\footnotetext{
${ }^{14}$ Ver Instituto Nacional de Estatísticas de Portugal - Inquérito dos Museus de 2009. Disponível em: <http://www.imc-ip.pt/pt-PT/recursos/estatisticas/Content Detail.aspx>. Acesso em: 12 mar. 2014.
} 
A segunda representação mais comum, que parece ter sido construída mais recentemente e talvez demonstre preocupação em atingir o grande número de turistas brasileiros, que cresce a cada ano, é a que evidencia as ligações de Portugal com o Brasil por intermédio de personagens importantes para a história do país e que são portuguesas. Nesse caso, ressalta-se ao mesmo tempo a importância de Portugal para a história do Brasil. Assim, as figuras de Pedro Álvares Cabral e de D. Pedro IV (I do Brasil) e sua família real - D. João $\mathrm{VI}$-, que viveu no Brasil por 13 anos, são as principais personagens dessa relação. No Palácio Nacional de Queluz, de onde a família real portuguesa partiu rumo ao Brasil em 1807, são várias

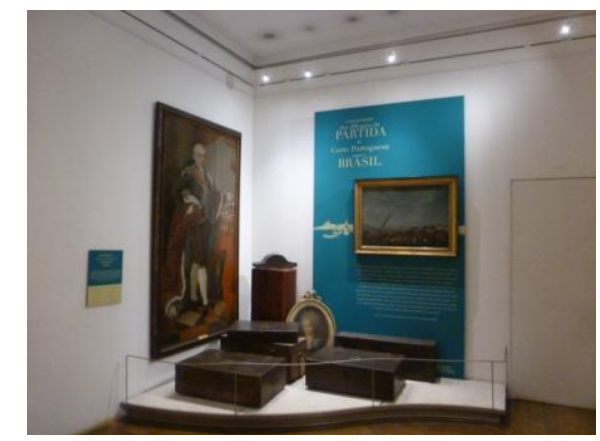

Figura 1 - Exposição que evidenciaa partida da família real para o Brasil. Museu dos Coches, Fonte: Foto de Sandra P. L. de C. Guedes. Acervo da autora. 13 mar.2014

as referências ao Brasil. Destacam-se o quarto em que faleceu D. Pedro IV, o primeiro imperador do Brasil, e vários quadros e textos que ressaltam personagens das famílias reais portuguesa e brasileira nos diversos cômodos do palácio.

A relação da família real portuguesa com o Brasil também está salientada em uma pequena exposição localizada em um canto no pavimento superior do Museu Nacional dos Coches (figura 1), para onde se dirigem em grande número turistas brasileiros que ficam encantados com a sua ligação, pela história, com o país visitado. 
Se em Lisboa ou nas cidades com palácios onde a família real portuguesa viveu, como é o caso de Mafra e Queluz, a ligação com o Brasil se faz por esse vínculo - D. João VI e sua família -, nas cidades mais afastadas da capital o vínculo se dá por meio de Pedro Álvares Cabral, o "descobridor" do Brasil.

Nos museus e/ou monumentos em que Cabral é o centro das atenções, o Brasil aparece como o objeto conquistado e a cultura que ali existe ainda hoje é consequência do espírito colonizador português. Essa representação aparece principalmente em cidades do interior do país que poderiam, com isso, atrair uma parcela dos milhares de turistas que visitam a capital. Fato interessante de se registrar é a presença de três túmulos de Cabral em diferentes cidades do país: Lisboa, no Panteão (figura2), ao lado de Vasco da Gama, Nuno Álvares Pereira, Luís de Camões e do Infante D. Henrique; em Belmonte, no Panteão dos Cabrais (figura3), cidade onde Cabral nasceu e para onde foram transferidos os restos mortais existentes em Santarém, em 1961; e em Santarém (figura4), em que Cabral faleceu e que, apesar de seus restos mortais terem sido transferidos para Belmonte, ainda preserva e divulga o túmulo de Cabral na Capela de Santa Maria da Graça.

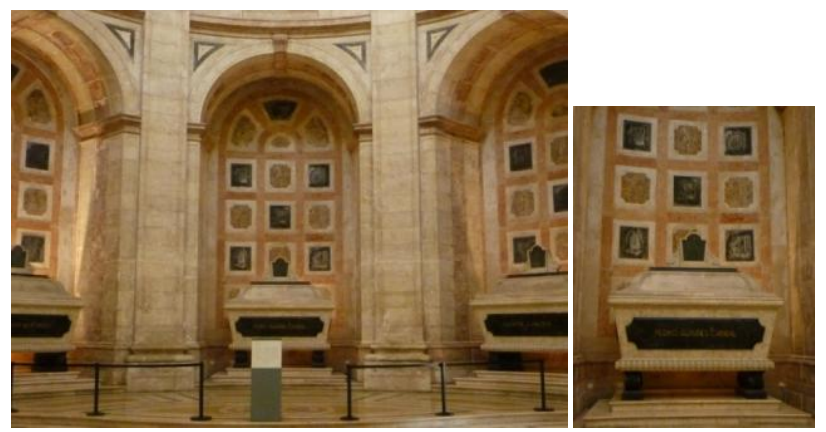

Figura 2 - Túmulo de Cabral no Panteão de Lisboa

Fonte: Foto de Sandra P. L. de C. Guedes. Acervo da autora. 8 mar. 2014 


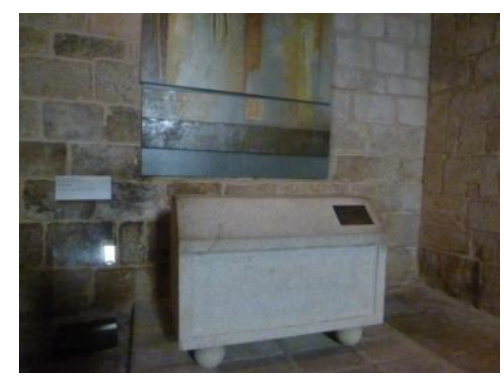

Figura 3 - Túmulo de Cabral em Belmonte Fonte: Foto de Sandra P. L. de C. Guedes. Acervo da autora. 25 abr. 2014

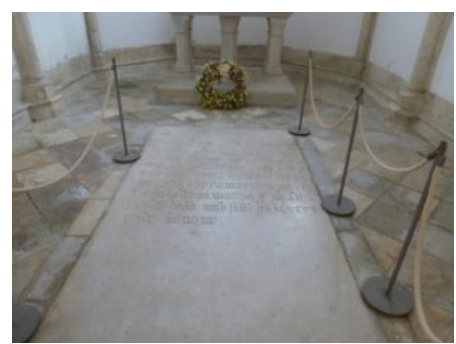

Figura 4 - Túmulo de Cabral em Santarém, Fonte: Foto de Sandra P. L. de C. Guedes. Acervo da autora. 20 abr. 2014

Percebe-se em Belmonte e Santarém uma competição pelo status de qual das duas é a "cidade mais brasileira", ambas contando com túmulo, estátuas e museus que celebram o Brasil e Álvares Cabral. Em Belmonte, bandeiras do Brasil e de Portugal tremulam em várias partes da cidade, como mostra a figura 5 , além de haver ali o Museu do Descobrimento; o Castelo dos Cabrais (figura6), onde teria vivido o avô de Pedro Álvares; uma praça com estátua de Cabral; e o já citado Panteão dos Cabrais, em que está um dos três túmulos do "descobridor" do Brasil. 


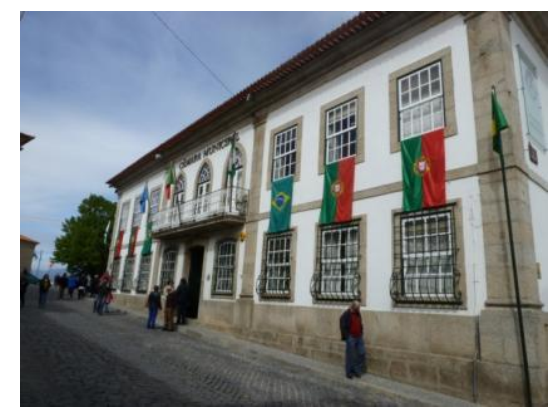

Figura 5 - Câmara Municipal de Belmonte. Bandeira do Brasil ao contrário, Fonte: Foto de Sandra P. L. de C. Guedes. Acervo da autora. 25 abr. 2014

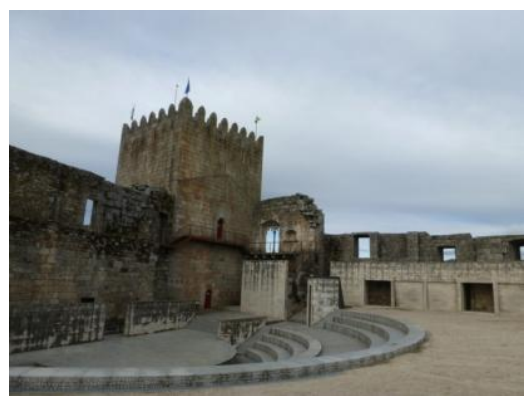

Figura 6 - Castelo dos Cabrais em Belmonte.Bandeiras do Brasil e de Portugalnatorre, Fonte: Foto de Sandra P. L. de C. Guedes. Acervo da autora. 25 abr. 2014

O Museu do Descobrimento ${ }^{15}$ evidencia, de forma bastante romântica, a viagem de Cabral e o legado português ao Brasil. Em grande parte da exposição, a natureza exuberante brasileira é destacada, e faz-se a descrição do país em várias partes da exposição com base na carta de Pero Vaz de Caminha, que é repetida em diferentes situações em partes e em sua totalidade. 0 estereótipo do indígena como "bom selvagem" e a visão da escravidão como uma necessidade que acabou trazendo importantes ganhos culturais ao país são claros na exposição, que chega a colocar em pé de igualdade a presença de escravos e de

\footnotetext{
${ }^{15}$ Inaugurado em abril de 2009 e concebido pela empresa Arqueohoje.
} 
imigrantes no Brasil ao afirmar no texto inicial da exposição, entre outras coisas, que "a entrada de escravos e imigrantes foi um fator essencial ao desenvolvimento populacional durante o período colonial e o império, até meados do século XX". A narrativa da exposição leva o visitante a sentir a inseparável relação do Brasil com Portugal, sendo os aspetos mais polêmicos da história comum de ambas as nações cuidadosamente tratados e minimizados ${ }^{16}$.

Do mesmo modo, o Castelo dos Cabrais faz relação direta entre o monumento e os antepassados do "descobridor do Brasil", salientando em textos e imagens (figura 7) que a família de Pedro Álvares Cabral viveu naquele local.

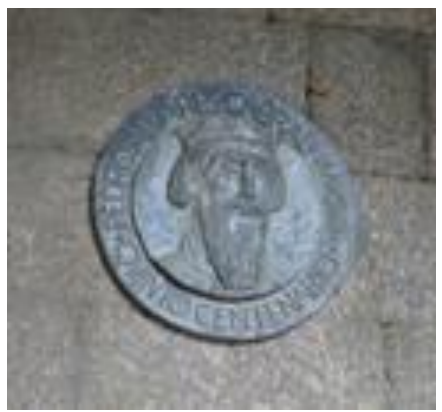

Figura 7 - Placa comemorativa do V Centenário de Cabral, Castelo de Belmonte, Fonte: Foto de Sandra P. L. de C. Guedes. Acervo da autora. 25 abr. 2014

\section{Considerações finais}

Este artigo discutiu duas das principais representações sobre - Brasil e os brasileiros encontradas nos museus portugueses pesquisados, ambas ligadas ao passado histórico que une Brasil e Portugal. Denota-se que a mais comum dessas representações evidencia a visão de Brasil já presente nos museus do século XIX, ou

${ }^{16}$ Por sua complexidade, esse assunto será tema de outro artigo. 
seja, como uma colônia portuguesa produtora de muita riqueza natural, principalmente ouro. A outra representação observada também ressalta a relação histórica dos dois países, mas essa relação é salientada pela importância de algumas personagens portuguesas para a história do Brasil, destacando-se Pedro Álvares Cabral, D. Pedro, I do Brasil e IV de Portugal, e D. João VI.

Percebe-se que os avanços ou retrocessos do Brasil, os avanços historiográficos e as representações criadas pela mídia ou pela troca de experiências mais recentes não aparecem na maioria dos museus portugueses, apesar de os dados estatísticos mostrarem um intenso e frequente trânsito de brasileiros e portugueses entre os dois países. A manutenção de representações criadas no século XIX, sobretudo nos museus mais visitados, leva-nos a novos questionamentos: são essas as representações que o público visitante quer ver ou se trata de um descaso com relação à atualização dessas exposições? Deve-se ainda salientar que representações que consideram o Brasil atual surgem em alguns museus específicos. A representação do Brasil como o país do futebol, por exemplo, encontra-se nos museus do Benfica e do Sporting, em Lisboa, onde o sucesso dos brasileiros nesse esporte é reverenciado. Outras, no entanto, mostram em destaque personalidades brasileiras, mas sem identificá-las como tais, como é o caso de Óscar Niemeyer e dos irmãos Fernando e Humberto Campana, no Museu do Design e da Moda em Lisboa, dados intrigantes e que procuraremos aprofundar em outros trabalhos.

\section{Referências}

Almeida, J.R. P. de. (2000).Instrução pública no Brasil (15001889):história e legislação. 2. ed. São Paulo: Educ/Inep/MEC.

Bôas, L.P.S.V.; Sousa, C.P. de. (2007).Representações sociais e história: limites e possibilidades. In: Moreira, A. S. P. \& Camargo, B. V. (Orgs.). Contribuições para a teoria e o método de estudo das representações sociais. João Pessoa: Editora da UFPB. 
Chagas, M. (2002). Memória e poder: dois movimentos. Cadernos de Sociomuseologia, 19, 43-81.

(2009). A imaginação museal. Museu, memória e poder em Gustavo Barroso, Gilberto Freyre e Darcy Ribeiro. Rio de Janeiro: Minc/Ibram.

Chartier, R. (1990). A história cultural: entre práticas e representações. Lisboa: Difel.

Estrada, M.L.V. (2012). Los museos: territorios simbólicos. In: Coordinación Nacional de Artes Plásticas. Cartografía de prácticas expositivas. México, D.F.: Instituto Nacional de Bellas Artes.

Fairclough, N. (2001). Discurso e mudança social. Brasília: Editora da Universidade de Brasília.

Fundação Oriente. Museu do Oriente. (2014).[Disponível em http://www.museudooriente.pt/209/o-museu.htm, consultado em 16/3/2014].

Horta, J. (2014). Turismo brasileiro em Portugal fechou 2013 com crescimento de 7,4\%. Portugal Digital[Disponível em http://portugaldigital.com.br/turismo/ver/20083663-turismobrasileiro-em-portugal-fechou-2013-com-crescimento-de-74, consultado em 27/10/2014].

Instituto Brasileiro de Geografia e Estatística (IBGE). (2000).Brasil: 500 anos de povoamento. Rio de Janeiro. Apêndice: estatísticas de 500 anos de povoamento. pp. 226 [Disponível em http://brasil500anos.ibge.gov.br/estatisticas-do-

povoamento/imigracao-por-nacionalidade-1884-1933, consultado em 27/10/2014]. 
Instituto dos Museus e da Conservação (IMC-IP). (2014). [Disponível emhttp://www.imc-ip.pt/pt-

PT/recursos/estatisticas/ContentDetail.aspx, consultado em 12 mar. 2014].

Instituto Nacional de Estatísticas de Portugal. (2009). Inquérito dos museus de 2009. [Disponível emhttp://www.imc-ip.pt/ptPT/recursos/estatisticas/ContentDetail.aspx, consultado em 12/3/2014].

Jodelet, D. (2007) Imbricações entre representações sociais e intervenção. In: Moreira, A. S. P. \& Camargo, B. V. (Orgs.). Contribuições para a teoria e o método de estudo das representações sociais. João Pessoa: Editora Universitária da UFPB.

Malheiros, J.M.(Org.). (2007). Imigração brasileira em Portugal.Lisboa: Paulinas [Disponível em http://www.oi.acidi.gov.pt/docs/Col_Comunidades/1_ImigrBrasileir a.pdf, consultado em 27/10/2014].

Moscovici, S. (2003). Representações sociais: investigações em psicologia social. Petrópolis: Vozes.

Santos, M. S. dos.(2004). Museus brasileiros e política cultural. Revista brasileira de Ciências Sociais, 19, 55, 53-72[Disponível em http://www.scielo.br/cgi-bin/wxis.exe/iah/, consultadoem 2/11/14].

Terra. Brasil deve se manter como 7. ${ }^{a}$ economia do mundo. (2014). [Disponível emhttp://economia.terra.com.br/pib- mundial/, consultado em 27/1/2015]. 